\title{
A Case of Native Cytomegalovirus Pancreatitis Following Deceased-Donor Renal Transplantation
}

\author{
J.J. Schwartz ${ }^{1, *}$, B. Woods ${ }^{2}$ and F. Shihab ${ }^{3}$ \\ ${ }^{I}$ Department of Surgery, Section of Transplantation, University of Utah, School of Medicine, Salt Lake City, Utah, \\ 84132; ${ }^{2}$ University of Utah, School of Medicine, Salt Lake City, Utah, 84132 and ${ }^{3}$ Department of Nephrology, Univer- \\ sity of Utah, School of Medicine, Salt Lake City, Utah, 84132, USA
}

\begin{abstract}
Cytomegalovirus (CMV) is a known cause of pancreatitis in immunocompromised patients, usually in association with the human immunodeficiency virus [1]. A handful of cases have been reported of CMV pancreatitis occurring in a transplanted pancreas secondary to immunosuppression associated with organ transplantation. Herein, we report a rare case of CMV pancreatitis following deceased-donor renal transplantation in which a patient's native pancreas was infected by CMV transmitted by donor renal tissue. After seroconversion from a CMV-positive donor, a 41 year old female with a history of autosomal dominant polycystic kidney disease presented with pancreatitis in her native pancreas following deceased donor renal transplantation, thus illustrating how a patient's native pancreas can be infected by CMV from donor renal tissue.
\end{abstract}

\section{INTRODUCTION}

CMV is one of the most common transplant-related opportunistic infections and will cause rejection of organs in up to $50 \%$ of cases without prophylaxis [2]. It has also been shown to increase susceptibility to other pathogens [3]. In renal transplantation, it has been associated with apthous ulcers, esophagitis, small bowel ulcers, diarrhea, large bowel hemorrhage, post-transplanational diabetes, and pancreatitis, among others [4]. In addition to causing primary disease, activation of latent disease in the recipient has been shown to occur following renal transplantation, with the highest risk group being CMV-negative recipients of CMV-positive donors $[5,6]$.

In a handful of cases, CMV pancreatitis has developed in the transplanted pancreas following simultaneous pancreaskidney transplantation $[7,8]$. This report describes the rare case of a deceased-donor kidney acting as a CMV vector for disease transmission and the subsequent results in inflammation of a patient's native, non-transplanted pancreas.

\section{CASE PRESENTATION}

A 41 year old CMV-negative female with a history of autosomal dominant polycystic kidney disease underwent deceased-donor renal transplantation from a CMV-positive donor. Cold ischemia time was twenty-six hours. The procedure was otherwise unremarkable. Postoperatively, however, the kidney was relatively oliguric and the post-refusion biopsy of the donor kidney demonstrated signs of antibodymediated rejection consisting of thrombotic microangiopathy. Due to the biopsy findings in the setting of delayed graft

*Address correspondence to this author at the Department of Surgery, Section of Transplantation, University of Utah, School of Medicine, Salt Lake City, Utah, 84132, USA; E-mail: Jason.Schwartz@ hsc.utah.edu function, the patient underwent three courses of plasmapheresis.

For the purposes of induction, the patient received five doses of Thymoglobulin $(1.5 \mathrm{mg} / \mathrm{kg})$ at the time of transplant. Thereafter, maintenance consisted of triple immunosuppression, mycophenolate mofetil $1000 \mathrm{mg}$ twice daily, tacrolimus $4 \mathrm{mg}$ twice daily, and a conventional steroid taper. Target tacrolimus levels were between 10 and $12 \mathrm{ng} / \mathrm{mL}$. Because of donor-recipient CMV mismatch, the patient was given valgancyclovir $450 \mathrm{mg}$ twice daily for 30 days posttransplant. Additional prophylaxis consisted of TMP-sulfamethoxone as well as fluconazole.

On the day prior to discharge, a mercapto-Acetyl-TriGlycine (MAG-3) radionucleotide scan showed prompt homogenous renal blood flow as well as activity within the bladder during the nephrogram phase. After an initial period of relative oliguria, her urine output was approximately 60 $\mathrm{mL}$ per hour on the day of discharge. This correlated with a drop in the patient's creatinine, which decreased from 3.7 $\mathrm{mg} / \mathrm{dL}$ on postoperative day 1 to $2.7 \mathrm{mg} / \mathrm{dL}$ on the day of discharge.

Her subsequent course is depicted in Fig. (1). In brief, the patient was admitted one month later with malaise and fever as well as severe volume depletion secondary to vomiting and diarrhea. Serum creatinine was $1.8 \mathrm{mg} / \mathrm{dL}$ at this time. Five months thereafter, her serum creatinine was $1.1 \mathrm{mg} / \mathrm{dL}$, at which time she was treated at an outside facility for pancreatitis of an unknown etiology. She returned to our facility five days following the second hospitalization due to severe abdominal pain and a lipase of $759 \mathrm{U} / \mathrm{L}$, again, with normal renal function (creatinine $=1.1 \mathrm{mg} / \mathrm{dL}$ ). Computed tomography of the abdomen as well as magnetic resonance imaging proved to be equivocal, and were essentially normal. Ultrasonography and magnetic resonance cholangiopancrea- 


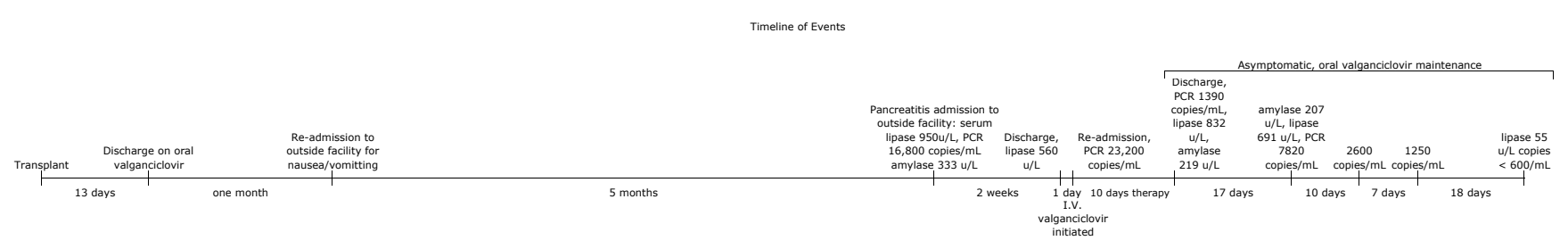

Fig. (1). Timeline of events.

tography (MRCP) demonstrated a dilated common bile duct, although no evidence of stones, anomalous pancreatic duct insertion, calcifications, or a pancreatic mass were noted (Fig. 2). At this time there was mild bandemia (bands $=9$ $\mathrm{K} / \mu \mathrm{L}$ ) but no other evidence of infection. Her white blood count was $3.62 \mathrm{~K} / \mu \mathrm{L}$ and her blood glucose was 88 . Her serum glutamate oxalate transferase was $43 \mathrm{U} / \mathrm{L}$. Other pertinent laboratory values included hematocrit of $29 \%$, calcium of $7.8 \mathrm{mg} / \mathrm{dL}$, and a serum amylase of $333 \mathrm{U} / \mathrm{L}$ which was measured on the day prior to admission. Serum lactate dehydrogenase was not measured at the time of admission. CMV infection was confirmed by quantitative PCR demonstrating a viral load of 16,800 copies per $\mathrm{mL}$. The patient was reinitiated on oral valganciclovir (single dose of $900 \mathrm{mg}$ daily), following which the patient's lipase levels dropped to 560 $\mathrm{U} / \mathrm{L}$ after a two week hospital stay.

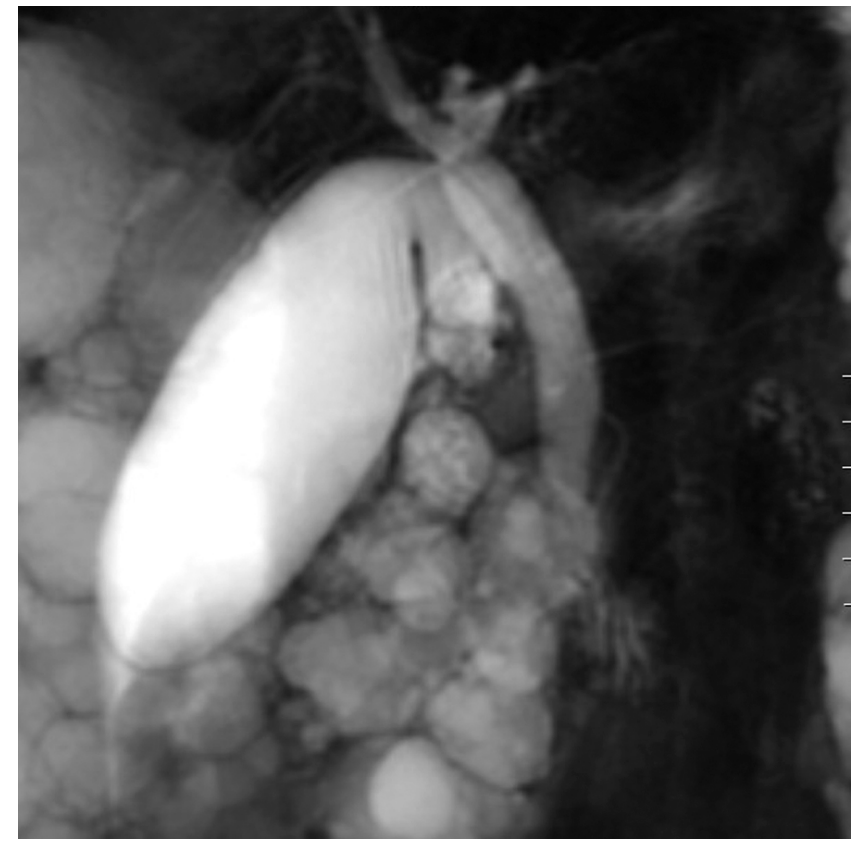

Fig. (2). MRCP demonstrating a dilated common bile duct against the background of polycystic kidneys.

When she was eventually discharged the patient returned the following day due to severe abdominal pain, at which point her quantitative CMV PCR level had risen to 23,200 copies per $\mathrm{mL}$, prompting the administration of intravenous gancyclovir. After 10 days of therapy, the patient's symptoms improved and the number of CMV copies per $\mathrm{mL}$ fell to 1390; however, her amylase and lipase still remained elevated Following discharge, the patient has continued on oral valgancyclovir and has had no further complications of CMV pancreatitis, despite persisting CMV DNAemia.

\section{DISCUSSION}

As many as $61 \%$ of renal transplant recipients contract CMV (with or without symptomatic infection) in the absence of antiviral prophylaxis [9], although CMV pancreatitis occurring in a patient's native pancreas after renal transplantation has only rarely been described $[10,11]$. In a randomized, placebo-controlled clinical trial, Balfour and colleagues were the first to show that the incidence of symptomatic CMV infection in renal transplant recipients was decreased when CMV prophylaxis was given. Only $7.5 \%$ of patients contracted symptomatic CMV infection during the first year by treating patients with prophylactic acyclovir following renal transplantation, compared to $28 \%$ in two placebo groups [11]. Acyclovir has largely been supplemented by ganciclovir [12] and by valganciclovir in high-risk kidney transplant recipients [13]. Recent reports, however, have begun to illustrate the emergence of cytomegalovirus resistance in patients who received valganciclovir prophylaxis [14].

The CMV-positive renal transplant group at the highest risk for serious complications of CMV infection are CMVnegative recipients that seroconvert from donor tissue [15]. With evidence of CMV viremia, the patient under review was originally treated with oral ganciclovir, but this proved insufficient as a first course of therapy, perhaps indicating the need for more aggressive antiviral therapy in higher risk groups as suggested by Eid et al. [14]. Arguably, this patient should have received anti-viral treatment after her first admission for pancreatitis.

Common causes of pancreatitis include gallstones; alcohol; medications such as steroids, NSAIDS, and azathioprine; and trauma. In rare cases, viruses such as the mumps virus and CMV cause pancreatitis. During the workup of this patient's pancreatitis, common etiologies were excluded from the differential. The possibility of biliary stone disease was considered, but was excluded based on negative ultrasound and MRCP findings which demonstrated a dilated common bile duct, but no stones. Even though MRCP has demonstrated near equivalency with endoscopic retrograde cholangiopancreatography (ERCP), the possibility does exist that a passing stone could have induced pancreatitis before these studies were performed [16]. It should also be noted that both ganciclovir and valganciclovir have been associated with an increased risk of pancreatitis in HIV patients, secondary to increased didanosine adsorption, but have not been independently shown to be causative factors [17]. In the case of allograft CMV pancreatitis, diagnosis is usually established on the basis of allograft biopsy demonstrating cytoplasmic inclusions and dense, large-staining nuclei [7]. However, due to the temporal relationship of this patient's 
presentation, computed tomography findings suggestive of acute pancreatitis, CMV viremia, and the correlation of symptom resolution with a fall in CMV viral load, a biopsy of the patient's native pancreas was deferred and it was concluded that the origin of this patient's pancreatitis was most likely CMV transmitted from the donor organ.

In summary, this case demonstrates a rare cause of pancreatitis and an atypical manifestation of CMV. In light of antiviral-resistant strains of the CMV that are emerging in the community in response to anti-viral prophylaxis, this case illustrates the need for a higher level of suspicion for CMV as the cause of pancreatitis and other rare CMVassociated diseases in post-transplantation patients.

\section{REFERENCES}

[1] Wolf P, Reiser JR, Fellow JE, Haghighi P. Pancreatitis in patients with AIDS presumptively due to CMV. J Clin Lab Anal 1989; 3 (3): 152

[2] Levitsky J, Freifeld AG, Puumala S, et al. Cytomegalovirus viremia in solid organ transplantation: does the initial viral load correlate with risk factors and outcomes? Clin Transplant 2008; 22 (2): 222.

[3] von Muller L, Schliep C, Storck M, et al. Severe graft rejection, increased immunosuppression, and active CMV infection in renal transplantation. J Med Virol 2006; 78 (3): 394.

[4] Smith RM. CMV prophylaxis: a useful step towards prevention of post-transplant diabetes? Diabetologia 2004; 47 (9): 1473.

[5] Sia IG, Patel R. New strategies for prevention and therapy of cytomegalovirus infection and disease in solid-organ transplant recipients. Clin Microbiol Rev 2000; 13 (1): 83.

[6] Lowance D, Neumayer HH, Legendre CM, et al. Valacyclovir for the prevention of cytomegalovirus disease after renal transplantation. International Valacyclovir Cytomegalovirus Prophylaxis Transplantation Study Group. N Engl J Med 1999; 340 (19): 1462.
[7] Klassen DK, Drachenberg CB, Papadimitriou JC, et al. CMV allograft pancreatitis: diagnosis, treatment, and histological features. Transplantation 2000; 69 (9): 1968.

[8] Backman L, Brattstrom C, Reinholt FP, Andersson J, Tyden G. Development of intrapancreatic abscess--a consequence of CMV pancreatitis? Transpl Int 1991; 4 (2): 116.

[9] Balfour HH, Jr., Chace BA, Stapleton JT, Simmons RL, Fryd DS A randomized, placebo-controlled trial of oral acyclovir for the prevention of cytomegalovirus disease in recipients of renal allografts. N Engl J Med 1989; 320 (21): 1381.

[10] Orug T, Arda K, Tosun O, Ozcay N, Atan S. The value of computed tomography in the diagnosis of acute necrotising pancreatitis in a renal transplant patient. HPB (Oxford) 2004; 6 (1): 49.

[11] Peterson PK, Balfour HH Jr, Marker SC, Fryd DS, Howard RJ, Simmons RL. Cytomegalovirus disease in renal allograft recipients: a prospective study of the clinical features, risk factors and impact on renal transplantation. Medicine (Baltimore) 1980; 59 (4): 283.

[12] Flechner SM, Avery RK, Fisher R, et al. A randomized prospective controlled trial of oral acyclovir versus oral ganciclovir for cytomegalovirus prophylaxis in high-risk kidney transplant recipients. Transplant 1998; 66 (12): 1682.

[13] Ciancio G, Burke GW, Mattiazzi A, et al. Cytomegalovirus prophylaxis with valganciclovir in kidney, pancreas-kidney, and pancreas transplantation. Clin Transplant 2004; 18 (4): 402.

[14] Eid AJ, Arthurs SK, Deziel PJ, Wilhelm MP, Razonable RR. Emergence of drug-resistant cytomegalovirus in the era of valganciclovir prophylaxis: therapeutic implications and outcomes. Clin Transplant 2008; 22 (2): 162.

[15] Schnitzler MA, Woodward RS, Brennan DC, Spitznagel EL, Dunagan WC, Bailey TC. The effects of cytomegalovirus serology on graft and recipient survival in cadaveric renal transplantation: implications for organ allocation. Am J Kidney Dis 1997; 29 (3): 428.

[16] Sakai Y, Tsuyuguchi T, Tsuchiya S, et al. Diagnostic value of MRCP and indications for ERCP. Hepatogastroenterology 2007; 54 (80): 2212.

[17] Cochochia J, McNichol I. Valganciclovir: an advance in cytomegalovirus therapeutics. Ann Pharmacother 2002; 36: 1075-9.

(c) Schwartz et al.; Licensee Bentham Open.

This is an open access article licensed under the terms of the Creative Commons Attribution Non-Commercial License (http: //creativecommons.org/licenses/ by-nc/3.0/) which permits unrestricted, non-commercial use, distribution and reproduction in any medium, provided the work is properly cited. 